breathable air, then we have gained the most important constituency. It is, after all, the public who pay the taxes, who buy the products, and who vote in elections. Just as with other environmental issues, if the public is won over, then the engineers and policy makers (eventually) must follow along.

In this paper I highlight efforts around the world that have been particularly noteworthy in the cause of reducing light pollution by educating the public. Radio interference is also of great harm to astronomers, but it will be covered only briefly in this paper because very little has been done to educate the public about the radio problem. This is because radio pollution is a more abstract and technical concept for the average person, as well as because many of the problems are addressable at the international (World Telecommunications Union) and national levels. With light pollution, however, the battles are more often on a local stage.

The premier organization fighting light pollution and educating the public about it is the International Dark-Sky Association (www.darksky.org/ ida/index.html), based in Tucson, Arizona, USA, and with over 2000 members in 69 countries. Over the past ten years IDA, largely through the person of David Crawford, has been able to not only preserve dark skies for observatories, but more significantly convince a great number of lighting engineers and public officials that it's in their own best interest to use lighting systems that are also beneficial to astronomers. Exterior lighting for streets and buildings that does not shine upwards saves a great deal of money, does its job much more efficiently and safely, and is aesthetically more pleasing. An alliance has been forged between those on all sides who are "enlightened" and it is steadily growing in its size and influence. For the cause IDA has produced 7 slide sets, 120 information sheets, and 2 videotapes.

The best way to check other major efforts around the world is to visit the Web sites linked to IDA's site. For example, in the United Kingdom the Campaign for Dark Skies (CDS) has also been effective in its educational and political efforts. Their booklet Starry, Starry Night, produced in conjunction with the Council for the Protection of Rural England, is first-rate in promoting dark skies and good lighting practices. CDS has also promoted "Star Watch UK", a project for schools and other youth groups to count the stars visible in a well-defined area of the sky. This type of program has also been done in Canada and the USA, and especially in Japan, where it was funded by the national Environmental Agency. Based on these amateur data, maps were constructed for sky brightness all around Japan. Even more than the maps, the real value of such projects is the increased awareness they bring to the public of deteriorating sky conditions. Many other examples, from countries such as Switzerland, Holland, Italy, and Spain, are discussed in the full paper.

\title{
16. PUBLIC EDUCATION TO PRESERVE DARK SKIES AND ASTRONOMICAL WINDOWS WITH EAVESDROPPING AND ROBOTIC TELESCOPES
}

\section{J. E. F. Baruch (Robotic Observatories)}

\section{Abstract}

It is suggested that the only guarantee for the preservation of dark skies is the guarantee that exists in the hearts of the people around the world. This paper notes how rising living standards and increasing GNP are associated with light pollution destroying the heritage of the night sky. It argues that it is necessary to decouple light pollution from rising living standards. A contribution to this process is to provide indices that are easily understood and useable for measuring the quality of the night sky.

It is shown how robotic telescopes can provide access to the night sky for people in the developed world through programmes which provide education, involvement in astronomy rescarch and access to the leading edge of astronomy through the new technique of eavesdropping. These education programmes will help to bring an understanding of the value of our heritage that belongs to our grandchildren: The Night Sky.

\section{THE ISSUES OF SPACE DEBRIS AND NEAR-EARTH OBJECTS AT THE UNITED NATIONS}

H. J. Haubold (United Nations Office for Outer Space Affairs)

The focal point of the United Nations activities in the field of peaceful uses of outer space is the Committee on the Peaceful Uses of Outer Space (COPUOS), set up in 1959 by the Gencral Assenbly. Since its establishment, the Committee and its two subcommittees (the Scientific: and 
Technical Subcommittee and the Legal Subcommittee) have resulted in five legal instruments, all of which have entered into force, as well as four sets of principles adopted by the United Nations General Assembly on the conduct of space activities, including astronomical satellite missions (http://www.seas.columbia.edu/ ah297/un.html):

\section{Treaties}

The 1966 Treaty on Principles Governing the Activities of States in the Exploration and Use of Outer Space, including the Moon and Other Celestial Bodies ("Outer Space Treaty") provides that space exploration shall be carried out for the benefit of all countries, irrespective of their degree of development. It also seeks to maintain outer space as the province of all mankind, free for exploration and use by all States and not subject to national appropriation. The 1967 Agreement on the Rescue of Astronauts, the Return of Astronauts and the Return of Objects Launched into Outer Space ("Rescue Agreement") provides for aiding the crews of spacecraft in the vent of accident or emergency landing, and establishes a procedure for returning to a launching authority a space object found beyond the territorial limits of that authority. The 1971 Convention on International Liability for Damage Caused by Space Objects ("liability Convention") provides that the launching State is liable for damage caused by its space objects on the Earth's surface or to aircraft in flight and also to space objects of another State or person or property on board such objects. The 1974 Convention on Registration of Objects Launched into Outer Space ("registration Convention") provides that launching States shall maintain registries of space objects and furnish specified information on each space object launched, for inclusion in a central United Nations Register (maintained by the United Nations Office for Outer Space Affairs). The 1979 Agreement Governing the Activities of States on the Moon and Other Celestial Bodies ("Moon Agreement") elaborates in more specific terms the principles relating to the Moon and other celestial bodies set out in the 1966 Treaty and sets up the basis for the future regulation of exploration and exploitation of natural resources found on such bodies.

\section{Principles}

The Declaration of Legal Principles Governing the Activities of States in the Exploration and Use of Outer Space (1963). The Principles Governing the Use by States of Artificial Earth Satellites for International Direct Television Broadcasting (1982). The Principles Relating to Remote Sensing of the Earth from Outer Space (1986). The Principles Relevant to the Use of Nuclear Power Sources in Outer Space (1992).

\section{Space Debris}

Space debris are all man-made objects in Earth orbit or reentering the dense layers of the atmosphere that are non-functional with no reasonable expectation of their being able to assume or resume their intended functions or any other functions for which they are or can be authorized, including their fragments and parts. The item on space debris was included into the agenda of the Scientific and Technical Subcommittee at its 1994 session; since 1995 the Subcommittee continued its consideration of this item on a priority basis. Member States and relevant international organizations are currently providing information on practices in minimizing the creation of space debris and the effects of this environment on space systems, including those used for astronomical purposes (http://www.un.or.at/00SA_Kiosk/).

\section{Near-Earth Objects}

Pursuing an understanding of Earth's interactions with near-Earth objects and adverse environmental impacts on astronomy have become issues of global research. In an effort to provide a scientific basis for future cooperative international research and space exploration, The Explorers Club and the United Nations Office for Outer Space Affairs organized an international conference on near-Earth objects (A. Carusi, T. Gehrels, and S. Isobe in Near-Earth Objects: The United Nations International Conference, Ed. J. Remo, Annals of the New York Academy of Sciences 822 (1997) $632 \mathrm{pp}$.). The forthcoming United Nations Conference on the Exploration and Peaceful Uses of Outer Space in 1999 at Vienna, Austria, may provide a forum to review such issues in depth.

The views, interpretations, and opinions presented in this paper do not necessarily reflect the position of the United Nations.

\section{BILATERAL AGREEMENTS, ZONING, INTERNATIONAL PROTOCOL}

S. Isobe (National Astronomical Observatory) 